\title{
Aero Engine Compressor Cooling by Water Injection - Part 1: Evaporative Compressor Model
}

\author{
David Alejandro Block Novelo and Uyioghosa Igie \\ School of Aerospace Transport and Manufacturing, Cranfield University, Cranfield, UK
}

\begin{abstract}
The need for more fuel-efficient turbofan engines has led to a rise in compressor pressure ratio and turbine inlet temperature respectively. The latter has been possible with advancements in turbine blade technology. Nevertheless, this higher temperature during combustion increases the production of thermal Nitrogen Oxides. Contrary to this high-pressure, high-temperature aero-engine design trend, regulations are pushing towards capping or reducing emissions. Injecting atomised water into a jet engine is an alternative to mitigate Nitrogen Oxides that is applied extensively to stationary gas turbines. The application for jet engines is very limited and dates back to the early Boeing 707 and 747 for thrust augmentation. The focus of this study is to investigate the performance benefits of water injection when applied to 2 and 3-spool compressors, under a wide range of different environmental conditions, and for different injection properties. In this first paper, a thermo-analytical compressor model with water droplet investigations in the Lagrangian frame of reference is explored. The methodology is applied to two different engine architectures, representative of modern turbofan engines. This water injection study focuses on cooling the core and shows that the percent reduction in compressor discharge temperature is promising over a wider range of ambient conditions than expected. The effect of droplet sizes or quantity utilised were seen to be more influential. The 3-spool compressor also appears to benefit more from water injection, mainly due to the higher operating pressures and temperatures found on the Intermediate Pressure Compressor which enables more efficient evaporation, as compared to a booster compressor. Given the design of this compressor, two locations of injections were considered. Reductions in Compressor Discharge Temperature of 60 and $80 \mathrm{~K}$ were seen for the 2 and 3-spool engines, for a $2 \%$ injection ratio, accompanied by reductions in specific compressor work of 16 and 17\%. Part 2 of this study has considered boundary conditions obtained here, to investigate the performance and emissions of complete jet engines.
\end{abstract}

Keywords: compressor, water injection, evaporation, cooling, droplets, turbofan

\section{1- Introduction}

The rise in air travel demand estimated at 5\% per year [1] has brought optimism about the future of the civil aviation industry. This, of course, has been met with more public discourse and regulations related to increasing environmental impact. Block and Igie [2] shows different measures focused on mitigating the environmental impact of aviation at and around airports. The study points out that most of the proposed solutions are focused on reducing $\mathrm{CO}, \mathrm{HC}$ and $\mathrm{CO}_{2}$. Only a few measures address Nitrogen Oxides $\left(\mathrm{NO}_{\mathrm{x}}\right)$ emissions. Daggett et al. [3] estimate a $47 \%$ reduction in $\mathrm{NO}_{\mathrm{x}}$ when $2 \%$ water to air ratio is injected into the core flow of the engine. The mechanism for this reduction is the cooling of the thermodynamic cycle, which also reduces the specific compressor work, enabling higher useful work outputs. With this improvement in pressure ratio, less fuel can be utilised for the same thrust requirement, which brings about an improvement in the Specific Fuel Consumption (SFC). The use of such a system on an aircraft, at take-off and climb when the engine is operated at peak Turbine Inlet Temperatures (TIT) also offers benefits in turbine blade creep life. This comes in an era where governments and companies have set emissions and noise limits as a key priority in aerospace research [4].

Water ingestion related to rain suction into a jet engine has been studied [5,6] and since 1998 there have been regulations in place to ensure that engines don't flame out under heavy rain conditions. Rain or runway splash ingestion has a negative effect on engine performance due to possible erosion, and a loss of momentum of the 
rotating parts, due to droplet impingement, apart from the resulting aerodynamic effects. Film forming on the blades decreases the aerodynamic efficiency of the compressor blade due to the alteration of the geometry and change in blade surface roughness [5]. Roumeliotis et al. [7] indicate that for some cases of rain ingestion, about $60 \%$ of the water ingested can remain unevaporated and reach the combustion chamber, causing a decrease in combustor efficiency or even flame-out.

Deliberate compressor water injection, however, is substantially different. The most important difference is that for this approach, atomised droplets of typically small diameters $(5-10 \mu \mathrm{m})$ are injected into the engine and have been observed to follow the flow path [8-11]. These droplets usually begin to evaporate in the initial/front stages of the compressor that brings about the cooling of the air flow (drop in temperature), increased density and moisture content. This procedure has been studied extensively through compressor analytical methods [11-14], through-flow approach, CFD approach [8,15-18], and experimental investigations [9,19-21] that have mostly focused on stationary gas turbines. For the analytical methods, Kim et al. [22] categorise the models into: natural convection model, diffusion model and Stokes model. The authors conclude that the three models agree with minor differences. The natural convection model is based on detailed droplet thermodynamics and accounts for sensible and latent heat transfers due to natural convection. A detailed analysis using this method is offered by Chaker et al. [23] and subsequently applied by Sanaye and Tahani [24], Zheng et al. [12] and Kim et al. [22].

The diffusion model assumes that the evaporation of the droplets occurs mainly due to mass concentration differences and ignores radiative and convective heat transfers. This approach was chosen as the main mechanism applied in this study, following Chaker et al. [23] conclusions that the droplet temperature will very quickly converge to the saturation temperature, hence the heat transfer term can be neglected. The diffusion model is described further, in a subsequent section. Hill [25] proposes the use of this model to offer a thermodynamic analysis implemented in White and Meacock [11]. Ref. [11] uses the diffusion model to evaluate the compressor operating point changes with water injection using through-flow methods, and proposes an expression for the evaporation rate for equilibrium evaporation. Zheng and Sun [12], subsequently applied these expressions and extend them to a non-ideal case for non-equilibrium evaporation. In the article, wet compression efficiency is defined and inlet fogging is compared to internal intercooling. The investigation gives a comprehensive insight into the thermodynamics of wet compression, but does not provide an expression for the evaporation rate and a constant value is used. The study shows the influence of compressor water injection on the polytropic coefficient of compression, which is smaller than that seen for the "dry" case. The reductions in compression specific work are evaluated and accounted for due to the fact that ideal compression will no longer be adiabatic but will have a heat transfer term due to water evaporation.

In a later investigation, White and Meacock [26] study multi-spool compressors and conclude that multi-spool engines adapt better to water injection due to the extra degree of freedom of the intermediate shafts. The results were confirmed with Bagnoli et al. [7] analytically, whose work is also taken here as the basis for the development of the compressor model. The research is validated against experimental results presented by Utamura et al. [9].

A similar outcome for a single shaft compressor was obtained by Roumeliotis and Mathioudakis [20], where experimental results on a single stage axial flow compressor are provided. Further experimental work was carried out by Favorskii et al. [19]. In the study, the authors note that the compressor specific work is reduced, but the mass flow is increased, giving as a result almost unchanged compressor power requirement for a $1.5 \%$ water to air ratio. The experiment is compared to an analytical method with good agreement.

The focus of most of the mentioned studies is the increment of thermal efficiency and power output of a gas turbine. The idea of using compressor water injection for $\mathrm{NO}_{\mathrm{x}}$ emission reduction in aircraft was studied by Daggett et al. [3,27], however, the impact of different environmental conditions in combination with water 
injection ratios have not been evaluated. There are currently no studies in the open literature that investigate different jet engine configurations and their performance changes during compressor water injection. To achieve indicative operating conditions in the engine models, a stand-alone compressor tool has been developed and it is the focus of this first part of the study. The outcomes are set as boundary conditions for the engine models in part 2 of this study. This study thus, is based on previous investigation of the science of water injection, and specifically achieves the following:

- Shows the drop in intermediate Compressor Discharge Temperature (CDT) as a function of water-toair ratio, droplet size and ambient conditions

- Highlights the changes in temperatures and hence evaporation rates for 2 and 3-spool compressors representative of modern aero-engines

- Evaluates the impact of injection location in the evaporation process and hence reduction in the intermediate CDT

\section{2- Evaporative Cooling Model}

To model a compressor's thermodynamic performance analytically, an estimated axial pressure distribution along the compressor length, an average axial velocity and compressor length are required. The pressure distribution can be obtained by means of Eq.(1), as indicated in Refs [11,14].

$$
P_{2}=P_{1} e^{c t}
$$

Where $P_{1}$ and $P_{2}$ are the inlet and exit stage pressures respectively, $c$ is the compression rate, which according to Refs.[11,14], amounts to $200 \mathrm{~s}^{-1}$, and $\mathrm{t}$ is the compression time.

With known flow velocity and axial length of the compressor, one droplet of water can be tracked through the compressor. The droplet absorbs sensible heat from the surrounding gas and uses it as latent heat of evaporation. As the droplets travel and follow the streamlines, they reduce in size and heat up. The surrounding air will be cooled while increasing its humidity or water vapour content.

The mass fraction of water vapour $(v)$ to dry air $(a)$ is known as the specific humidity of air $(\omega)$, which can be expressed in terms of the partial pressures of water vapour and dry air. The partial pressure of dry air will be the atmospheric pressure, $\mathrm{P}$, minus the partial pressure of water vapour, $\mathrm{P}_{\mathrm{v}}$,

$$
\omega=\frac{M_{v}}{M_{a}}=\frac{P_{v} / R_{v}}{P_{a} / R_{a}}=0.622 \frac{P_{v}}{P-P_{v}}
$$

If water is added to the dry air, $w$ will increase up to a maximum value after which further addition of water will condense in the air rather than humidify it. The relative humidity of a mixture relates the number of particles of vapour (number of moles) in dry air, compared to the maximum number of water particles that air can hold at a certain temperature and pressure. It can be computed as the ratio of the water vapour partial pressure in air, to the saturated vapour pressure of air at that same temperature, as in Eq. (3).

$$
R H=\frac{P_{V}}{P_{\text {sat } @ T}}
$$

Combining Eqs. 2 and 3, an expression that relates specific humidity to relative humidity and saturation pressure can be obtained as follows:

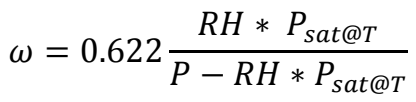


Also, the mass, internal energy and enthalpy of a mixture are the sum of the individual gas component contributions

$$
H_{m}=\sum_{i=k}^{N} m i * h i
$$

For a dry air-water vapour mixture, the enthalpy would be

$$
H_{m}=h_{m} m_{m}=h_{a} m_{a}+h_{v} m_{v}
$$

Where the subscript $m$, stands for water-vapour dry-air mixture. The enthalpy of water vapour is the sum of the required enthalpy to vaporize that quantity of water if it was in its liquid form to start with, plus the enthalpy due to the actual temperature compared to a $0^{\circ} \mathrm{C}$ datum.

$$
h v=h_{f g}+c_{p v} T
$$

The sensible heat lost by the air will be equal to the latent heat gained by the water, so the steady-state energy equation then becomes,

$$
\left(\dot{m}_{a} h_{a}+\dot{m}_{v} h_{v}\right)_{1}+\dot{m}_{w 1} h_{f}=\left(\dot{m}_{a} h_{a}+\dot{m}_{v} h_{v}\right)_{2}+\dot{m}_{w 2} h_{f}
$$

Where $h_{f}$ is the specific enthalpy of the liquid water at the injection temperature. The quantity of water injected, $\dot{m}_{w}$ is the difference between the initial and final absolute humidities, $w_{2}-w_{1}$. If all the water is evaporated, the second term, $m_{w 2}$ is equal to zero. Chaker et al. [23] shows how the water temperature quickly reaches the saturation temperature and remains constant throughout the evaporation process. Roumeliotis and Mathioudakis [28] present results for compressor water injection, accounting for change in water temperature. The results presented in this study assume constant water temperature and compare well with those presented by Ref. [28,29] as shown in Appendix A. From combining Equs. 4, 7, and 8, an expression for the energy balance that depends on known inlet conditions (temperature, and specific humidity) of the gas, the exit conditions can be derived. However, the exit specific humidity, $w_{2}$ depends on the saturation and ambient pressures. These values are dependent on the mixture temperature and can be computed using the correlations found in Saul and Wagner [30]. In this way, an equation that depends only on $T_{2}$ can be solved iteratively to obtain the saturation temperature and specific humidity of a water-vapour mixture (as shown in Appendix B).

The injected water, or injection ratio, $f$, will be equal to the mass of each droplet multiplied by the number of droplets per kilogram of dry air, $n$, assuming spherical droplets,

$$
f=\frac{4}{3} \pi r^{3} \rho_{l} n
$$

The decrease in mass of the liquid water must be equal to the rate of change of water vapour, by conservation of mass, so that

$$
-\frac{d f}{d t}=\frac{d w}{d t}=4 \pi r^{2} \rho_{l} n \frac{d r}{d t}
$$

Based on mass transfer, Spalding [31] provides the following expression for the rate of change of droplet size with time, which was later adapted by White and Meacock [11] and Bagnoli et al. [13] in terms of the fraction of mass of water vapour to mass of dry air $(w)$. The expression, known as diffusion model [32] can be found below, 


$$
\frac{d r}{d t}=\frac{\mathrm{D}_{v} \rho}{r_{d} \rho_{l}} \ln \left(\frac{1+w}{1+w_{l}}\right)
$$

The mass diffusion coefficient, $D_{v}$ is a function of pressure and temperature, and expressions for this are provided in Refs. [13,23,29,33]. The correlation proposed by Eckert [33] was chosen for this analysis.

From Eq. (10) an expression of the change in droplet diameter radius can be found

$$
r_{2}^{3}=r_{1}^{3}-\frac{3 \Delta \mathrm{f}}{4 \pi n \rho_{l}}
$$

The compression equation can be computed from Eq. (13)

$$
\frac{\mathrm{P}_{2}}{\mathrm{P}_{1}}=\left(\frac{T_{2}}{T_{1}}\right)^{n w e t}
$$

Where nwet is the polytropic coefficient of compression which will be lower for wet compression than it is for dry air. This variation also brings about a reduction in compression specific work. The formulation given by Zheng et al. [12] is shown in Eq.(14) considering a polytropic process.

$$
\begin{gathered}
n w e t=\frac{\gamma}{\gamma-1}+\frac{h_{f g}}{R_{a}} \frac{d w}{d T}-\left(\frac{1}{\gamma-1}\right)\left(\frac{n_{\text {poly }}-\gamma}{n_{\text {poly }}-1}\right) \\
n_{\text {poly }}=\frac{\eta_{\text {poly }} \gamma}{\eta_{\text {poly }} \gamma-\gamma-1}
\end{gathered}
$$

Equations (13), (14), and (15) help to determine the compressor exit temperature, however, the polytropic coefficient of compression depends on the term $\mathrm{dw} / \mathrm{dT}$, so an initial guess must be made for this evaporative rate. The equations can be solved iteratively for $\mathrm{T}_{2}$ and $\mathrm{dw} / \mathrm{dT}$. This term was considered constant by Zheng et al. [12], but was noticed to change as the droplet volume reduced, this methodology thus, is an extension of the model presented in Ref. [12], with a variable evaporative rate. The pressure, temperature, droplet diameter and moisture content, $w$ are computed at each time step. The final moisture content or absolute humidity is obtained from Eq. (10) and increases at each time step as water evaporates.

$$
w_{2}=w_{1}+\frac{d w}{d t} \Delta t
$$

\section{3- Compressors under Investigation}

Two and three-spool turbofan engine compressors, applicable to civil aviation, have been considered. As shown in Fig.1, the 2-spool design consists of a fan and booster compressor mounted on the same shaft and powered by a Low-Pressure Turbine (LPT). This configuration also consists of a high-pressure compressor (HPC), on a separate shaft, operating about 3 times the speed of the low-pressure spool [34]. The 3-spool turbofan configuration is also shown in Fig.1 and consists on a fan (low-pressure compressor - LPC) attached to a LPT followed by an intermediate pressure compressor (IPC) which spins 3.3 times faster than the LP spool. Finally, a HPC on a sperate shaft that spins 1.5 times faster than the IPC spool [35]. Table 1. Shows some of the design specifications for both compressors from fan to middle compressors sections (booster and IPC respectively) with the inclusion of the HPC PR. To minimize flow distortion in practice and the potential waste of water, the injection is considered behind the fan as shown in Fig. 1. This location of injection takes advantage of the rise in temperature of the flow exiting the fan, providing water injection benefits even in instances when the ambient temperature is low. For the 2-spool compressor, the water is assumed to be injected $144 \mathrm{~mm}$ away from the booster while for the 
3-spool compressor two positions are considered due to more space between the Fan and the IPC. These are P1Short Distance (SD) injection - $144 \mathrm{~mm}$ away from the IPC and P2- Long Distance (LD) injection - 400mm away from the IPC. The influence of droplet diameters $(2,5,10,15$ and $20 \mu \mathrm{m})$, injection ratios or water-to-air ratios (1-3\%), ambient temperatures $(278,288,298,303$ and 313K) and ambient relative humidity (30, 60 and $80 \%)$ were analysed for both compressors, all at same ambient pressure of $101 \mathrm{kPa}$. Each compressor, studied at a given water injection ratio and droplet diameter is compared to the corresponding dry case at the same ambient temperature and relative humidity.

Table 1 Specification of 2 and 3-spool compressors at take-off

\begin{tabular}{c|cccc} 
Engine Design & Fan PR & $\begin{array}{c}\text { Booster/ } \\
\text { IPC PR }\end{array}$ & $\begin{array}{c}\text { HPC } \\
\text { PR }\end{array}$ & $\begin{array}{c}\text { Injection } \\
\text { Distance (mm) }\end{array}$ \\
\hline 2-Spool & 1.65 & 2.36 & 8.4 & 144 \\
3-Spool & 1.6 & 5.16 & 5.16 & 144 and 400
\end{tabular}

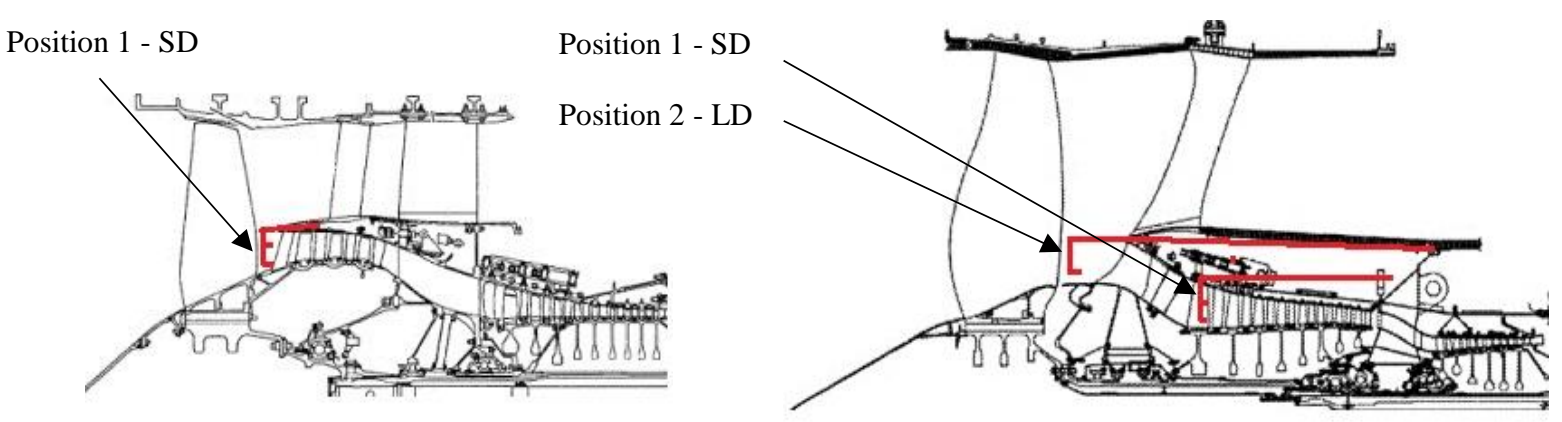

Figure 1 Cross-section of 2 (left) and 3-spool (right) compressor indicating injecting positions. Image adapted from [41]

\subsection{Two-spool Compressor Analysis}

\subsubsection{Effect of Ambient Conditions.}

Aircraft engines experience very different weather conditions depending on the take-off and landing destination. Figure 2 shows the gas temperatures from the fan intake $(x=0)$ to the inlet of the HPC $(x=1)$ for the case of dry compression $(f=0 \%)$ and different injection ratios. For a dry compression case, the temperature rises from ambient temperature $298 \mathrm{~K}\left(25^{\circ} \mathrm{C}\right)$ to $349 \mathrm{~K}\left(66^{\circ} \mathrm{C}\right)$ due to the compression that occurs in the fan. This value stays almost unchanged as the air flows through the duct between the fan and the booster and then increases as the air gets compressed again. Although the points on the curves are joined, for visual representation, the temperature increase would happen monotonically and not in straight lines due to the nature of the compression process. When the gas is atomized with water, however, a first temperature reduction is seen between the fan exit and the inlet of the booster. The higher the injection ratio, the more dramatic this temperature decrease will be. For a lower injection ratio of $1 \%$, the inlet fogging effect is small and the temperature only reduces in a few degrees. The water will then be ingested into the booster and the slope of the temperature curve will be affected due to the heat transfer term in the isentropic coefficient of compression (Eq. 14, 15). After the mixture leaves the booster, it will flow into a duct where the remaining water (if any) will evaporate providing further cooling to the HPC inlet. 


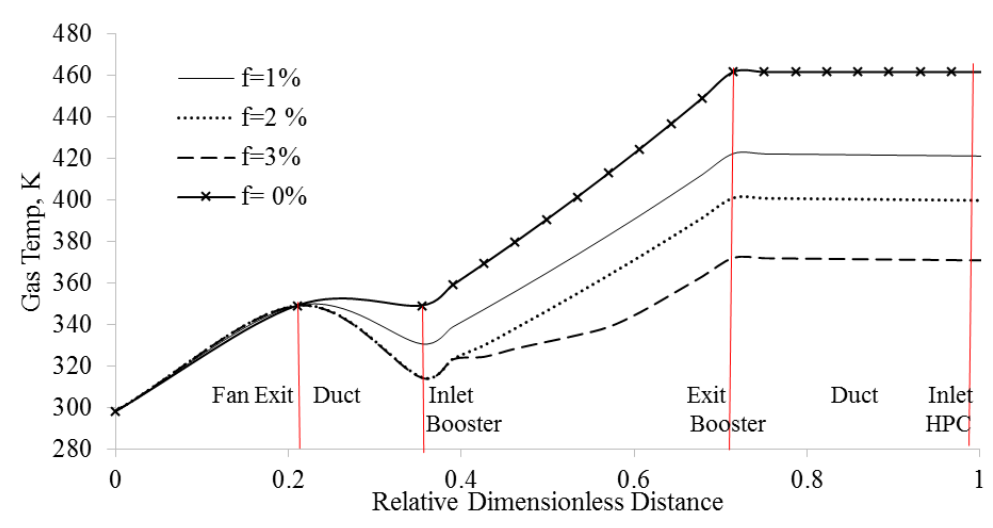

Figure $2 \mathrm{Gas}$ temperature from the intake to booster exit $(10 \mu \mathrm{m}$ and $60 \% \mathrm{RH})$

Although as seen in Fig.2, the booster exit temperature depends on the amount of water, the pressure ratio and the initial ambient temperatures, it will be seen that the reductions in the booster exit temperature (as a percentage of the dry value) are independent of the inlet ambient temperature. Figure 3 demonstrates the effects of injecting water at different ambient temperatures for a fixed injection ratio of $2 \%$ and relative humidity of $60 \%$. This figure shows the droplet evaporation based on droplet size reductions with respect to the actual compression time, from the inlet to the exit of the booster compressor. The droplet diameter reduction from an initial value of $5 \mu \mathrm{m}$ to a new value at $\mathrm{t}=0$ accounts for the evaporation that takes place in the duct before the droplet enters the booster, since water is injected $144 \mathrm{~mm}$ before the $1^{\text {st }}$ stage rotor of the booster. This initial reduction in droplet size is influenced by the ambient temperature as shown. The highest ambient temperature $\left(313 \mathrm{~K}\right.$ or $\left.40^{\circ} \mathrm{C}\right)$ considered leads to higher fan exit temperatures, causing the highest droplet size reduction compared to other ambient temperatures, with the least at $278 \mathrm{~K}$ or $5^{\circ} \mathrm{C}$. The figure shows that with time, the droplets become smaller, due to heat absorbed and used as latent heat of vaporization. At ambient temperatures below $278 \mathrm{~K}$, it is expected that the droplet will not fully evaporate in the booster but flow further into the HPC. As the droplets reduce in diameter from 5 to about $2.5 \mu \mathrm{m}$, the surface area-to-volume ratio increases linearly, and after this, the increment happens exponentially, and so the heat transfer becomes more effective; this and the increasing compressor temperature explain the sudden change in slopes seen on Fig.3.

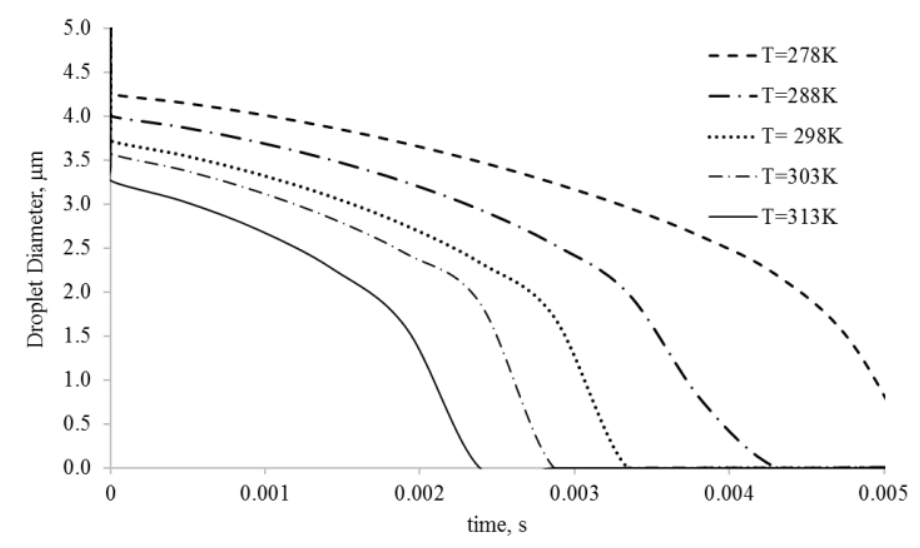

Figure 3 Effect of ambient temperature on droplet evaporation (2\% injection ratio at $60 \% \mathrm{RH})$

The effect of water injection at different ambient temperature on the booster exit temperature is shown on the lefthand side of Fig. 4 for $5 \mu \mathrm{m}$ droplets, compared to the "dry" case. This exit temperature reduction is seen to increase with an increase in the injection ratio. At $2 \%$ injection ratio, which is $2 \mathrm{~g}$ of water per $\mathrm{kg}$ of air, the temperature drops by $12 \%$ irrespective of the ambient temperatures investigated. Sexton et al. [10] report the same reduction for the same water quantity using an analytical tool to simulate a 16 stage compressor, while Sun et al. [16] shows a $10 \%$ reduction using through-flow methods on a 3-stage compressor mounted on a single shaft engine. There is a slight divergence in the temperature reduction with respect to the various cases of ambient temperatures at higher injection ratios that are attributed to incomplete evaporation (Fig.4 Left- $\mathrm{f}>2 \%$ ). 

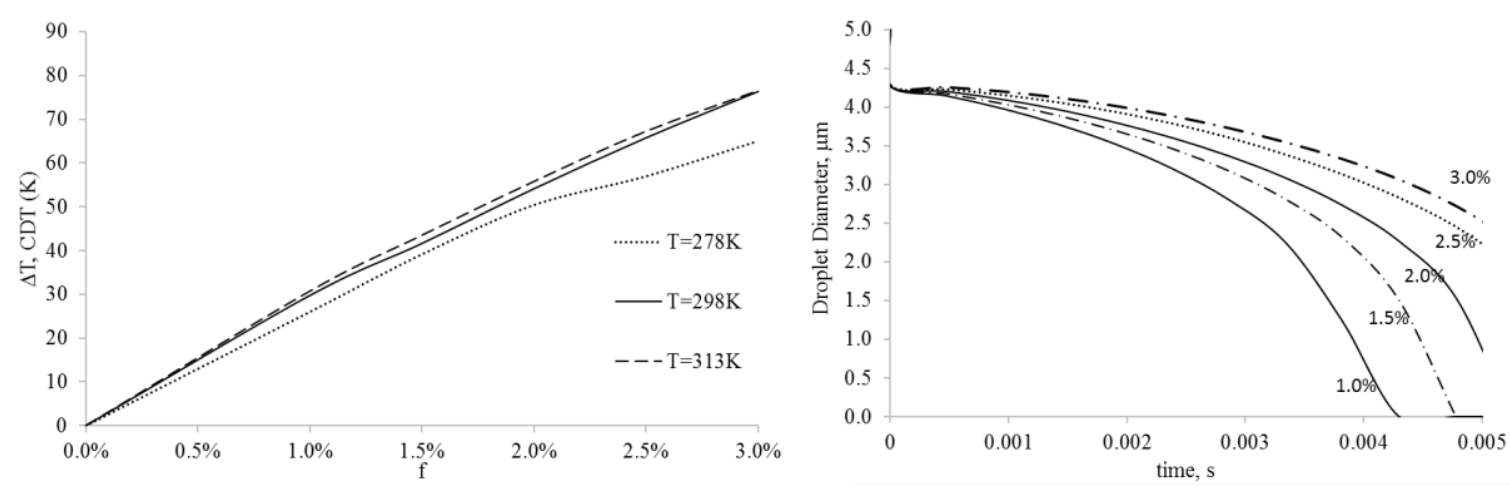

Figure 4 Influence of ambient temperatures on booster exit temperature drop for increasing injection ratio (left) and evaporation rate for injection ratios (right)

The right-hand side of Fig. 4 shows one case of ambient temperature $\left(278 \mathrm{~K}\right.$ or $\left.5^{\circ} \mathrm{C}\right)$, and the evaporation of $5 \mu \mathrm{m}$ droplet injected at varied injection ratio. At $2 \%$, the droplet does not evaporate completely at the booster exit as the droplet diameter is down to $1 \mu \mathrm{m}$. High injection ratios (2.5 and 3\%) create a larger heat sink; the sensible heat that is absorbed from the surrounding air is distributed into a larger mass. This is the reason why higher amounts of water have more cooling capacity (left) and last for longer in the booster (right). The results show that $2 \%$ injection ratio is a good compromise between maximizing the heat sink and ensuring complete/significant evaporation in the booster for ambient temperatures as low as $278 \mathrm{~K}$. It is important to indicate that for this $278 \mathrm{~K}$ case, the amount of evaporated water in the duct before the booster compressor was exactly $37.2 \%$ of the original injected value irrespective of the amount of injected water (only $62.8 \%$ flows into the booster). The relative humidity in the duct increased with increasing injection ratio, and so did the absolute amount of evaporated water. For example, $37.2 \%$ of $2 \mathrm{~g}$ of water is greater than $37.2 \%$ of $1 \mathrm{~g}$ of water, nevertheless, the proportion of evaporated water was always the same. This explains the linear relationships between booster exit temperature reduction and injection ratio, since the evaporation rate for an isolated droplet depends on the fluid density, mixture saturation conditions, droplet diameter and amount of water. If the residence time is the same, the proportion of evaporated water will also be the same irrespective of the number of droplets present in the flow (Fig 4-Left.).

The RH in a gas turbine has been studied by Refs. [36-38]. RH impacts the evaporation time because evaporation is a mass-diffusion process driven by temperature and mass concentration differences as indicated in Eq.11. The left-hand side of Fig. 5 shows that the booster exit temperature still decreases with injection ratio, with negligible influence at the different ambient RH (constant ambient temperature of $298 \mathrm{~K}-5 \mu \mathrm{m}$ ). The right of the figure shows that an increasing RH delays the evaporation time. Further details of the change in RH before and after injection is shown in subsequent results.
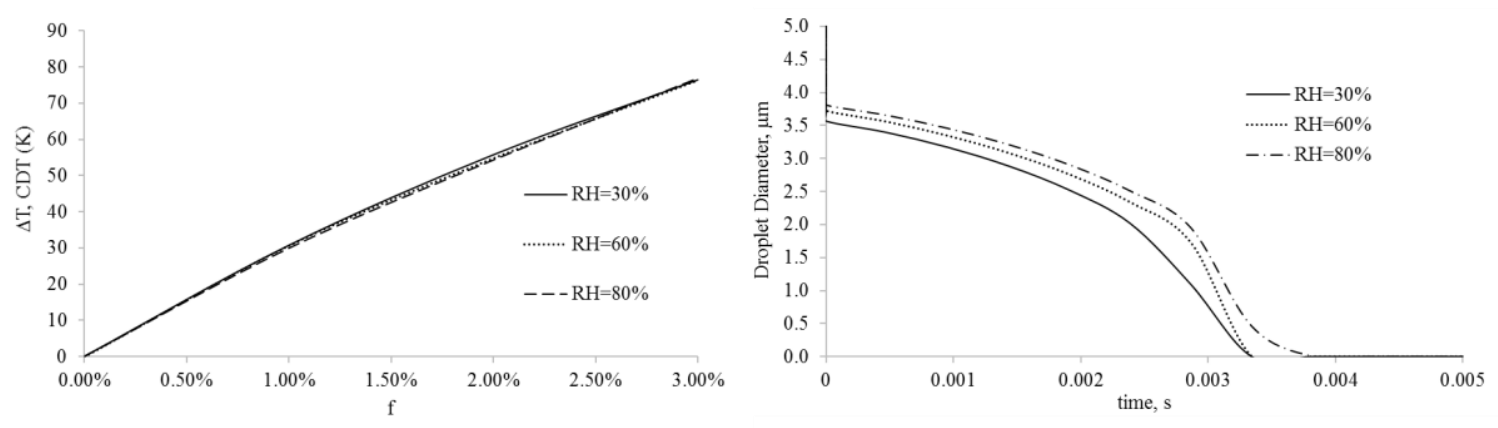

Figure 5 Booster exit temperature drop with injection ratio at different relative humidity (left) and the related evaporation rates (right)

Table 2 shows how the gas properties change when it goes from different ambient temperatures at $30 \%$ relative humidity to the fan exit/booster intake. The temperature drop achieved at the exit of the compressor for an injection ratio of $2 \%$ is also shown. The first thing to note is that the relative humidity drops considerably after the gas 
passes through the fan. The clear advantage of injecting after the fan is the enhancing of the evaporation effectiveness by injecting water at temperatures above $325 \mathrm{~K}$ and relative humidity below $5 \%$ (as opposed to $30 \%$ ). The next thing to note is that the saturation temperature at the booster inlet becomes almost constant. While the highest and lowest ambient temperatures differ by $11.2 \%$, the saturation temperatures after the fan only differ by $5.4 \%$. This property of the saturation temperature becoming almost independent of the ambient conditions increases with higher temperatures, and thus allows for a constant drop in booster exit temperature for a given water quantity. This drop in the 2-spool engine amounts to a reduction in about $10-12 \%$ of its "dry" operating temperature and is independent of the ambient conditions analysed here.

Table 2 Temperature reductions by evaporative cooling for $\mathrm{RH}=30 \%$

\begin{tabular}{lcccc}
$\begin{array}{c}\text { Ambient } \\
\text { Temperature } \\
(\mathrm{K}), \text { at 30\% RH }\end{array}$ & $\begin{array}{c}\text { Booster Inlet } \\
\text { temperature }(\mathrm{K})\end{array}$ & $\begin{array}{c}\text { Relative } \\
\text { Humidity at } \\
\text { booster inlet }\end{array}$ & $\begin{array}{c}\text { Saturation } \\
\text { Temperature } \\
\text { at booster } \\
\text { inlet }(\mathrm{K})^{*}\end{array}$ & $\begin{array}{c}\Delta \mathrm{T} \text { drop at } \\
\text { booster exit in } \\
\text { relation to dry } \\
(\mathrm{f}=2 \%)(\mathrm{K})\end{array}$ \\
\hline 278 & 325 & $3 \%$ & 302 & 50 \\
288 & 337 & $3 \%$ & 307 & 53 \\
298 & 344 & $4 \%$ & 311 & 54 \\
303 & 355 & $4 \%$ & 314 & 55 \\
313 & 367 & $5 \%$ & 319 & 56 \\
*Lowest temperature achievable by evaporative & & \\
cooling
\end{tabular}

\subsubsection{Effect of Water Injection Properties: Water Quantity and Droplet Size}

The increment in size of the water droplet is not an increase in the amount of water, as the injection ratio of $2 \%$ is the same for all the cases. An increase in droplet diameter amounts to the utilisation of fewer droplets, so the mass is distributed differently. Figure 6 on the left shows the gas temperatures for these different droplet diameters ranging from $2 \mu \mathrm{m}$ to $20 \mu \mathrm{m}$. Droplets larger than $10 \mu \mathrm{m}$ have particularly negligible effect in booster exit temperature. This is attributed to the lower surface-area-to-volume ratio found on larger droplets. A droplet diameter of $10 \mu \mathrm{m}$ has 4 times less surface area of $20 \mu \mathrm{m}$, nevertheless twice the surface-area-to-volume ratio, which reflects a more efficient evaporation process. As such, the case of $2 \mu \mathrm{m}$ indicates the best case of temperature drop in the compressor, with complete evaporation immediately after entry to the booster section, before 0.4 dimensionless distance. For $5 \mu \mathrm{m}$ droplet, this evaporation is achieved after 0.6 dimensionless distance (Fig.6Right), after which the slope of the temperature curve (Fig.6-Left) changes because the second term of Eq. (14) becomes 0 , and the polytropic coefficient of compression, that defines the temperature curve slope, is almost the same as that of the dry case. The 2 and $5 \mu \mathrm{m}$ droplets absorb more energy as they pass through the compressor booster as compared to the $10-20 \mu \mathrm{m}$ cases, causing a higher reduction in temperature. The left of the figure also captures the cooling/evaporation in the duct between the booster and the HPC, in the form of constant pressure evaporation for the larger diameter droplets that do not entirely evaporate inside the booster.
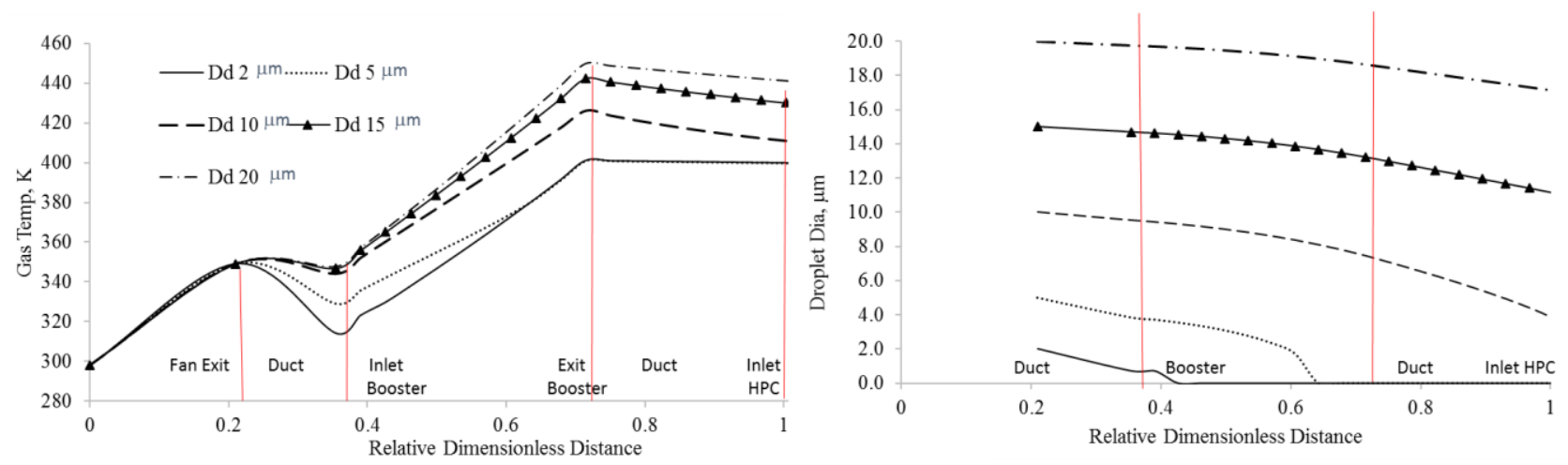

Figure 6 Gas temperature from the intake to booster exit ( $f=2 \%$, at $298 \mathrm{~K}$ and $60 \% \mathrm{RH}$ ) 
Figure 7 shows the reductions in the booster exit temperature for the range of droplet sizes discussed but for varied injection ratios up to $3 \%$. This figure shows an improvement in the booster temperature drop with increase in injection ratio. As indicated, the $2 \mu \mathrm{m}$ droplets are so efficient at evaporating that for injection ratios of $1,1.5$, and $2 \%$ the air gets saturated before it enters the compressor, and no further cooling is possible in the duct, that explains the small flattening of the curve between 1 and $2 \%$.

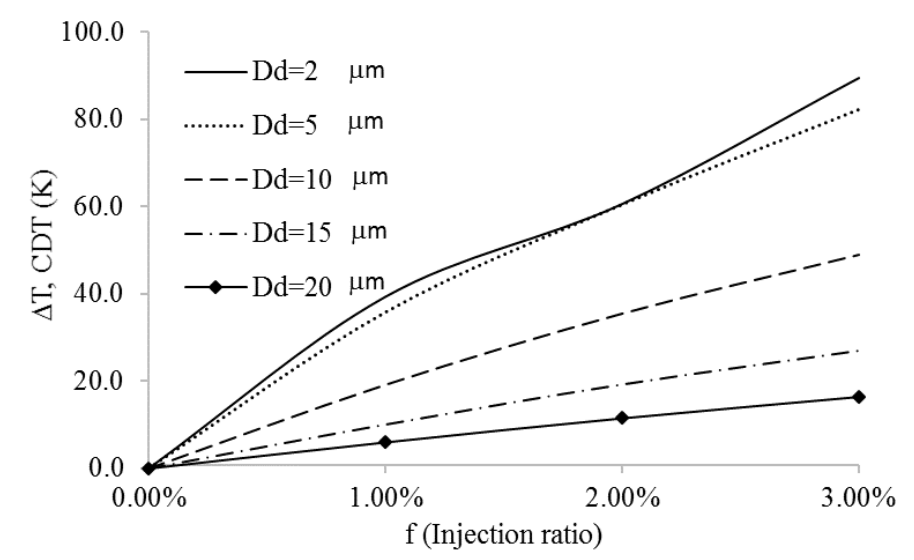

Figure 7 Booster exit temperature drop vs injection ratio for different droplet diameters

Previous studies, [39,40] show that when injecting $5 \mu \mathrm{m}$ droplets, $99.15 \%$ of the injected volume will follow the flow path without impacting the blades, braking or being centrifuged towards the casing. Since this model does not account for droplet brake-up or impact, and based on the promise found on $5 \mu \mathrm{m}$ droplets, this size will be used from now on.

\subsection{Three-spool Compressor Analysis and Comparison}

As mentioned previously, two injecting positions are considered for the 3-spool compressor. These are SD and LD positions. The latter allows for more evaporation of droplets before entry into the IPC. SD in this configuration is for direct comparison with the 2-spool compressor with only SD injection that is expected to cause farther intercooling comparatively, but less initial temperature drop in the duct than the LD position. Figures 8 and 9 show the gas temperature (left) and relative humidity (right) from the intake of the fan to the HPC inlet, for SD and LD respectively. The temperatures and relative humidites still represent a tracked particle through the flow, for different injection ratios with a droplet size of $5 \mu \mathrm{m}$. The gas temperature plots indicate the reduced gas temperature now expected with an increase in the injection ratio. As water is injected closer in the SD position case, the intercooling effect lasts for longer than in the LD case. In the SD cases (Fig.8), saturation is never reached in the duct before the IPC, and the initial temperature drop is smaller. However, the slope of the temperature curve maintains a lower value for an extended period due to the intercooling effect.
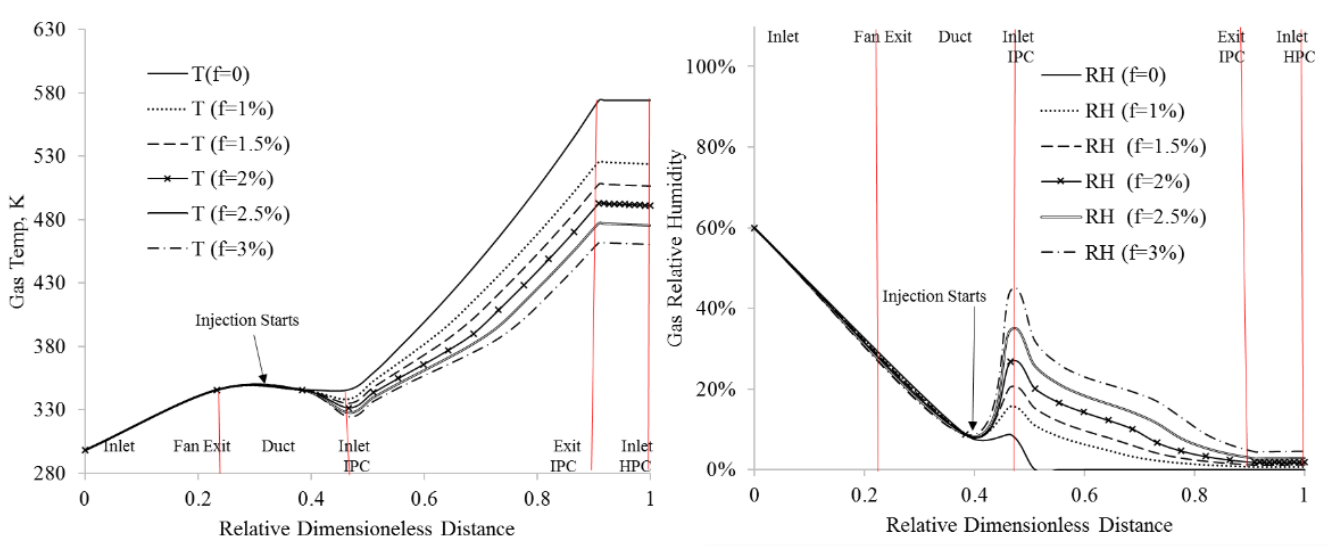

Figure 8 Gas temperature (left) and RH (right) across compressor at SD position for varied injection ratio 

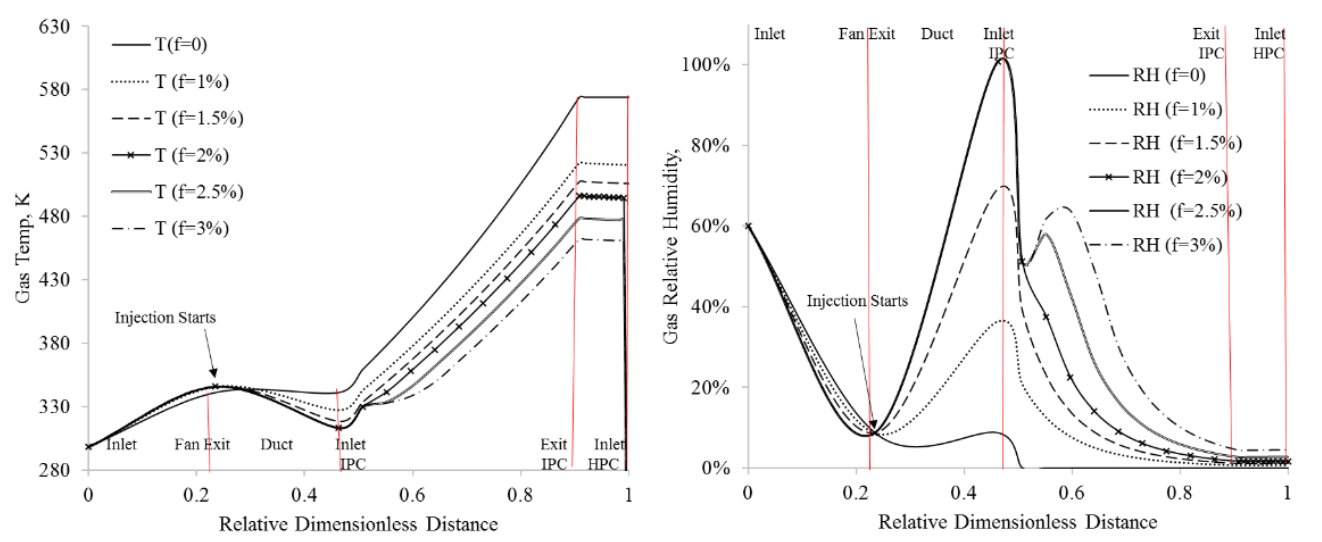

Figure 9 Gas temperature (left) and RH (right) across compressor at LD position for varied injection ratio

The trend of RH in Fig. 8 shows a decrease in RH across the fan that approaches zero in the duct before the IPC, for the dry case. A rise in $w P$ (Eq. 17, below), as a consequence of the FPR, occurs just after the Fan, but the denominator, in this case, becomes 10 times higher as a result of the increased temperature and its relationship to $\mathrm{P}_{\text {sat }}$, which has as a consequence a dramatic reduction in RH in the duct between the fan and the IPC (hence the small effect of CDT change with Relative Humidity seen on Fig. 5). With water injection, the RH increases in this duct (after the injecting point) until the IPC inlet where a second increase in temperature starts. The rise in RH in the duct occurs at constant pressure, as pressure losses are neglected. The drop in temperature of air, and increase in water vapour content, $w$, inside the duct, ensures that the vapour pressure approaches the saturation vapour pressure, raising the RH (Eq.17). For the LD position in Fig. 9, 100\% RH is reached for injection ratios from 2\% and above due to a further drop in temperature in the duct. Once the RH reaches $100 \%$ no further water evaporates, and the left-over water flows in liquid form into the IPC. The rise in temperature and pressure in the IPC generally causes reductions in the RH inside the compressor, as seen for the fan case. This sudden decrease in RH at the inlet of the IPC, creates favourable conditions for the water to evaporate again, and so fast evaporation is seen at this stage. Although the pressure in the first stage increases, the temperature is seen to stay almost constant (in the LD injection) due to the fast evaporation, and hence the RH rises again slightly at $x=0.6$. In subsequent stages, there is less available water, which means the cooling effects are diminished and so the denominator in Eq.(17) increases much more than the numerator, and the RH drops to almost 0 . In the cases where there is less available water $(\mathrm{f}<2 \%)$, the relative humidity is seen to decrease after the first IPC stage without the presence of the second peak. Khan and Wang [17] report a similar RH behaviour for the case of an 8-stage compressor, analysed with stage stacking techniques under equilibrium and non-equilibrium evaporation. On the temperature graph, (Figs.8\&9 Left) the point at which the temperature-curve slope changes coincide with the point where the water is fully evaporated, this behaviour is more obvious in Fig. 10.

$$
R H=\frac{w P}{P_{\text {sat }}(w+0.622)}=\frac{f(P, w)}{f(T, w)}
$$

The calculated drop in gas temperature at the exit of the IPC in relation to the dry case for both SD and LD positions are highlighted in Tab. 3. That of the 2 -spool booster compressor exit is also included, all at $298 \mathrm{~K}$ ambient temperature. The results for the 3-spool show that the drop in the IPC exit temperature for both positions is very similar given the axial length injecting difference of $256 \mathrm{~mm}$. The extra initial cooling on the LD position seems to be compensated by longer intercooling on the SD case. When comparing the two compressors at their exits (IPC and booster) for the same injection position, it can be observed that the drop in temperature of the 3 spool configuration is more significant. This is attributed to higher pressure and temperature ratio with respect to the work done up till this location. Figure 10 provides further evidence indicating that for the 2 -spool, the water droplets do not evaporate at the booster compressor, unlike the 3 -spool compressor in all the cases investigated. 
Table 3 IPC and booster $\Delta \mathrm{T}$ exit for different injection ratios

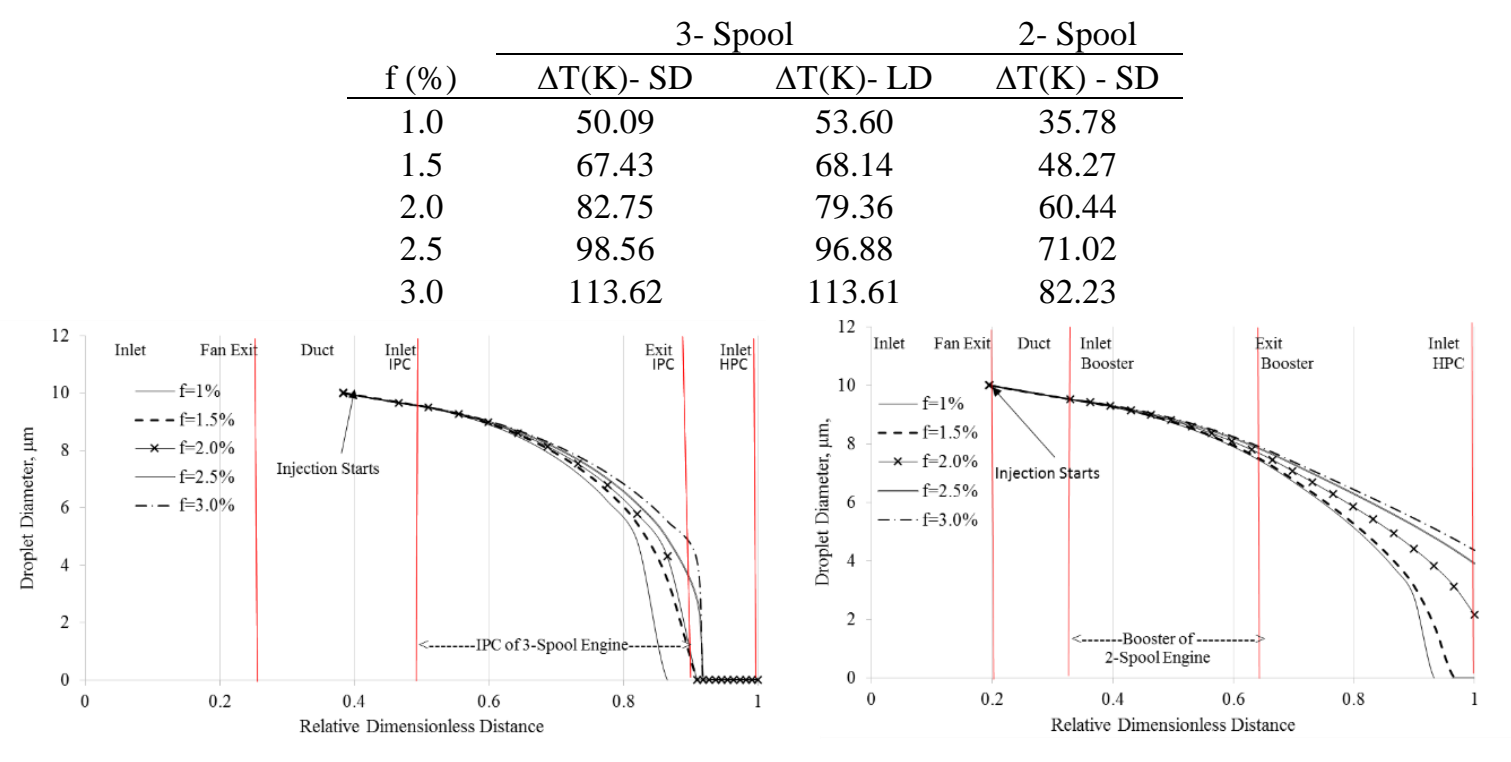

Figure 10.Comparison between droplet depletion on the 3 and 2-spool compressor for different injection ratios

Figure 11 complements Figs. 8 and 9, indicating the depletion of the droplets at SD and LD positions of the 3spool compressor using the same droplet size of $5 \mu \mathrm{m}$ for different injection ratios. In fact, for the case of $1 \%$ injection ratio, all the water is evaporated before the gas enters the IPC for the LD position, and the curves for diameter change diverge considerably during this initial inlet cooling. If the injecting position is moved closer to the IPC (at SD position), the water has less time to evaporate in the duct and it occurs inside the IPC compressor. This also infers the influence of injection position on the evaporation time.

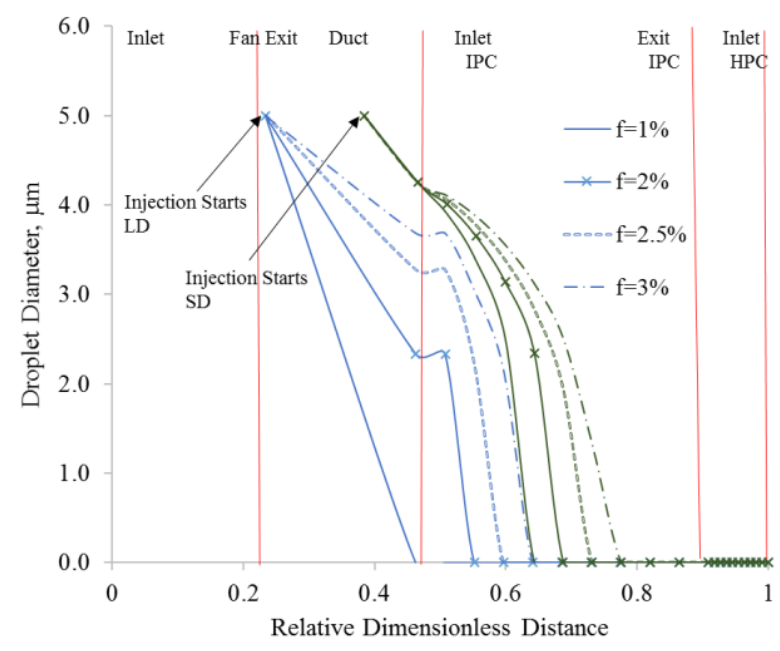

Figure 11 Droplet depletion for different injection ratios at SD and LD positions - 3-spool compressor

Figure 12 demonstrates the reductions in compressor specific work with water injection at SD position, calculated with the changes in enthalpy as shown in Eq. (8). The maximum reductions are about $22 \%$ for $2 \mu \mathrm{m}$ droplets and $12 \%$ for $10 \mu \mathrm{m}$, that is similar to outcomes of White and Meacock [11] that showed 18 and $12 \%$ for a subsonic compressor with a PR of 15 . The $2 \mu \mathrm{m}$ droplets in both cases of compressors evaporate very fast and reach saturation conditions in the duct, this explains the plateau seen between 1 and $2 \%$. Two processes are seen for small droplets; up to $1 \%$ injection ratio, the reduction in work is mainly due to the cooling of the gas before it enters the compressor. After $2 \%$ injection ratio, significant amounts of unevaporated water start flowing into the compressor, intercooling the gas as it gets compressed. For the $10 \mu \mathrm{m}$ droplets, the reductions are linear as saturation is not reached before the compressor inlet. The 2 -spool engine seems to have a comparatively higher 
reduction in specific work than the 3-spool, since the 2-spool engine has a short 3-stage booster, while the 3-spool engine has a longer 8-stage IPC. The implications of this are shown previously in Fig. 10. In the IPC, the water will evaporate before the exit of this intermediate compressor, and thus comparatively, the specific work decrease is less. In the shorter booster, the water will travel the whole length of the compressor and thus all the stages will get intercooled. Although the specific work reduces, depending on the operation of the gas turbine, the mass flow might increase, and the specific enthalpy change, when combined with the increase in mass flow, could result in an increased, decreased or unchanged compressor power consumption.

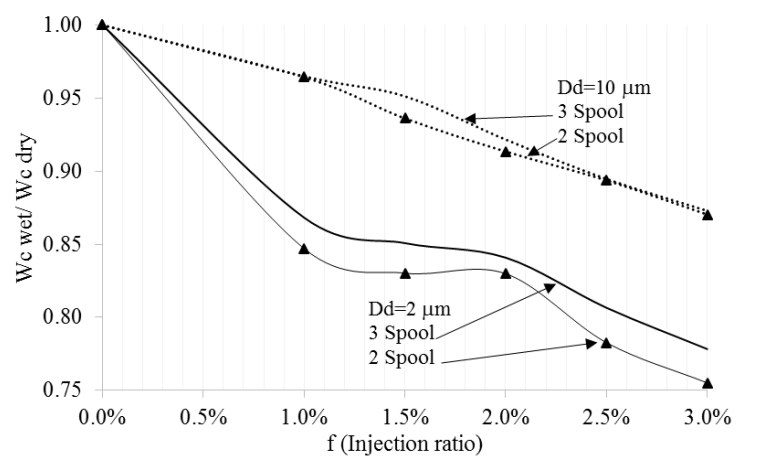

Figure 10 Reduction in compressor specific work due to injection ratio and droplet size for both compressors

\section{4- Assumptions and Limitations}

This model does not account for droplet breakup, interaction or for droplet-blade impaction. The simplification is a lot more applicable to droplets of up to $10 \mu \mathrm{m}$ diameters. For 15 and $20 \mu \mathrm{m}$ also investigated, there is a high degree of uncertainty due to other transport mechanisms that begin to be more influential. It is the assumption that the droplets are spherical and travel along the flow path.

All the simulations have been conducted at an ambient pressure of $101 \mathrm{kPa}$, and the pressure ratios of the fan and intermediate compressors are assumed constant. The off-design re-matching of the compressors caused by a change in the inlet conditions have not been accounted for. The off-design simulations for different ambient temperatures were later simulated for a gas turbine engine using the in-house software, TURBOMATCH, and the pressure ratios were compared for those of the stand-alone model as shown in Appendix C. The highest relative error in terms of booster exit temperature difference and pressure ratio is $1.34 \%$ and $2.67 \%$ respectively. Hence, this limitation in the stand-alone model does not lead major inaccuracies in the predictions for droplet evaporation.

Generally, the interpretation of the results is in parts not straightforward and depends on the saturation conditions of the duct between the fan and the following turbomachinery component.

\section{5- Conclusions}

This first part of the study has focused on a stand-alone evaporative compressor model exploring the effect of water injection behind the fan, at different ambient conditions, droplet size and injection rate. This allows for the necessary specification of boundary condition in part 2 study. The new findings unique to this study are:

- Internal compressor water injection still offers benefit in reducing the specific compressor work at low ambient temperature, given the rise in ambient temperature by the exit of the fan. About $2 \%$ injection ratio is a good compromise between maximizing the heat sink and ensuring complete/significant evaporation in the compressor for ambient temperatures as low as $278 \mathrm{~K}\left(5^{\circ} \mathrm{C}\right)$.

- The 3-spool compressor benefits more from this configuration of water injection than the 2-spool, due to higher operating intermediate compressor temperatures.

- The 2-spool engine seems to have a comparatively higher reduction in specific work than the 3-spool, since the 2-spool engine has a short 3-stage booster, while the 3-spool engine has a longer 8-stage IPC, 
and so all the stages are intercooled in the booster, while only about half of the stages are intercooled on the IPC.

- The SD and LD positions considered for the 3-spool compressor shows that the minimal influence of these relative positions in terms of reduction in IPC exit temperature. However, for the LD position, saturation is reached prior to entry into the IPC for injection ratios from $2 \%$ and above, and so longer intercooling is replaced by a larger drop at the entry of the compressor.

- The influence of ambient temperature and relative humidity for constant pressure shows that the same temperature drop can be achieved independently of the ambient temperature or humidity levels for the range considered here. This is due to the saturation temperature becoming almost independent of the air temperature at the positions where the water is injected, where the gas has reached $325 \mathrm{~K}$ or more.

More generally, the study verifies that:

- Smaller droplets for the same injection rate are more effective in reducing compressor operating temperatures, due to their higher surface-area-to-volume ratio. By controlling the droplet diameter, it is also possible to control the place at which the stages benefit from the highest cooling (where the slope of the diameter change curve becomes steeper).

- The initial reduction in droplet size is influenced by the ambient temperature and the fan pressure ratio. The booster or IPC exit temperature reduces with increase in injection ratio.

\section{Acknowledgments}

This work was supported by the Mexican National Council for Science and Technology (Conacyt), and by the Centre for Propulsion of Cranfield University.

\section{Nomenclature}

$\begin{array}{cl}\text { CDT } & \text { Compressor Discharge Temperature } \\ \mathrm{CO} & \text { Carbon Monoxide } \\ \mathrm{CO} 2 & \text { Carbon Dioxide } \\ \mathrm{Cp} & \text { Specific Heat }(\mathrm{J} / \mathrm{kgK}) \\ \mathrm{Dv} & \text { Mass diffusion coefficient }(\mathrm{m} 2 / \mathrm{s}) \\ \mathrm{Dd} & \text { Droplet Diameter }(\mu \mathrm{m}) \\ \mathrm{f} & \text { water injection ratio }(\mathrm{kgw} / \mathrm{kga}) \\ \Gamma & \text { Mass transport coefficient } \\ \gamma & \text { Specific heat ratio } \\ \eta & \text { Efficiency } \\ \mathrm{H} & \text { Enthalpy }(\mathrm{J}) \\ \mathrm{h} & \text { Specific enthalpy }(\mathrm{J} / \mathrm{Kg}) \\ \mathrm{HC} & \text { Hydrocarbons } \\ \mathrm{HPC} & \text { High-Pressure Compressor } \\ \mathrm{IPC} & \text { Intermediate Pressure Compressor } \\ \text { L= hfg } & \text { Enthalpy of vaporization }(\mathrm{J} / \mathrm{kgK}) \\ \text { LD } & \text { Long Distance } \\ \text { LPC } & \text { Low-Pressure Compressor } \\ \text { LPT } & \text { Low Pressure Turbine } \\ \mathrm{m} & \text { Mass flow rate }(\mathrm{kg} / \mathrm{s}) \\ \mathrm{n} & \text { Number of droplets } \\ \mathrm{P} & \text { Total Pressure }(\mathrm{Pa}) \\ \mathrm{PR} & \text { Pressure Ratio } \\ & \end{array}$

$\begin{array}{cl}\text { P2 } & \text { Position } 2 \\ \text { q } & \text { Specific heat transfer }(\mathrm{J} / \mathrm{Kg}) \\ \rho & \text { Density }(\mathrm{kg} / \mathrm{m} 3) \\ \mathrm{R} & \text { Gas Constant }(\mathrm{J} / \mathrm{kgK}) \\ \mathrm{r} & \text { Radius }(\mathrm{m}) \\ \mathrm{RH} & \text { Relative humidity } \\ \mathrm{SD} & \text { Short Distance } \\ \mathrm{t} & \text { Time }(\mathrm{s}) \\ \mathrm{T} & \text { Total temperature }(\mathrm{K}) \\ \mathrm{TIT} & \text { Turbine Inlet Temperature } \\ \mathrm{u} & \text { Internal energy }(\mathrm{J} / \mathrm{Kg}) \\ \mathrm{v} & \text { Flow velocity }(\mathrm{m} / \mathrm{s}) \\ \omega & \text { Specific humidity }(\mathrm{kgvap} / \mathrm{kgair}) \\ \mathrm{w} & \text { Specific Work }(\mathrm{J} / \mathrm{Kg}) \\ \mathrm{W} & \text { Work }(\mathrm{J}) \\ & \text { Subscripts } \\ 1 & \text { inlet } \\ 2 & \text { outlet } \\ \mathrm{a} & \text { air } \\ \mathrm{c} & \text { Critical temperature/ pressure } \\ \mathrm{m} & \text { mixture } \\ \mathrm{s} & \text { saturation } \\ \mathrm{v} & \text { vapour } \\ & \end{array}$




\section{Appendix A. Validation against other analytical methods}
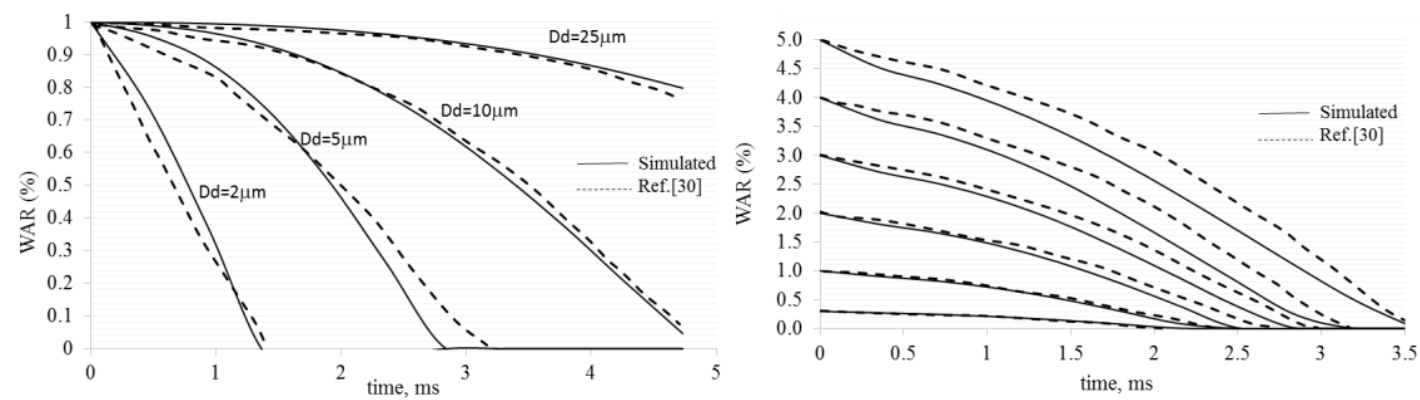

Figure A.1 Dependency of droplet diameter (Left) and water quantity (right) on evaporation time. Model vs Ref. [29]

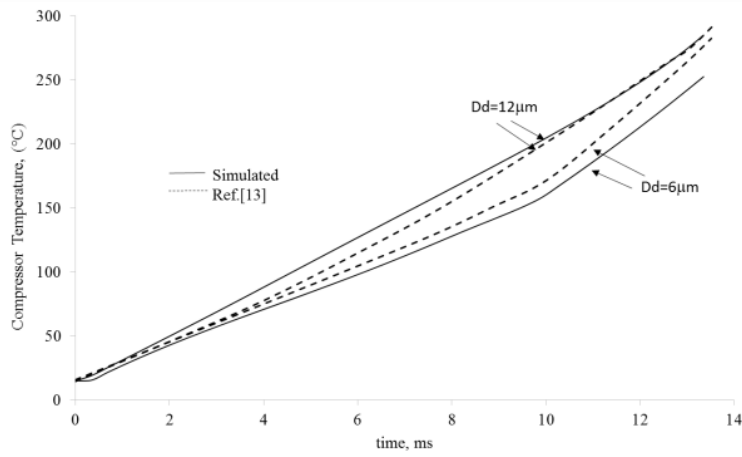

Figure A.2 Compressor Temperature for different droplet diameters. Model vs Ref.[14]

Table A.1 compares the CDT reductions between this model and the compressor of Ref.[14] For different injection ratios. The model presented here seems to over predict the temperature reduction compared to Ref.[14].This can be due to the assumption of constant water temperature as well as the fact that Ref.[14] Uses a different analytical model.

Table A.1 CDT reduction for different injection ratios. Model vs Ref [14]

\begin{tabular}{ccc}
$\mathrm{f}$ & $\begin{array}{c}\mathrm{CDT}_{\text {wet }} / \mathrm{CDT}_{\text {dry }} \\
\text { Simulated }\end{array}$ & $\begin{array}{c}\mathrm{CDT}_{\text {wet }} / \mathrm{CDT}_{\text {dry }} \\
\text { Ref.[14] }\end{array}$ \\
\hline $0 \%$ & 1.00 & 1.00 \\
$1 \%$ & 0.87 & 0.91 \\
$2 \%$ & 0.77 & 0.81 \\
$3 \%$ & 0.68 & 0.72 \\
$4 \%$ & 0.59 & 0.64
\end{tabular}




\section{Appendix B. Calculation and Iteration Procedure}

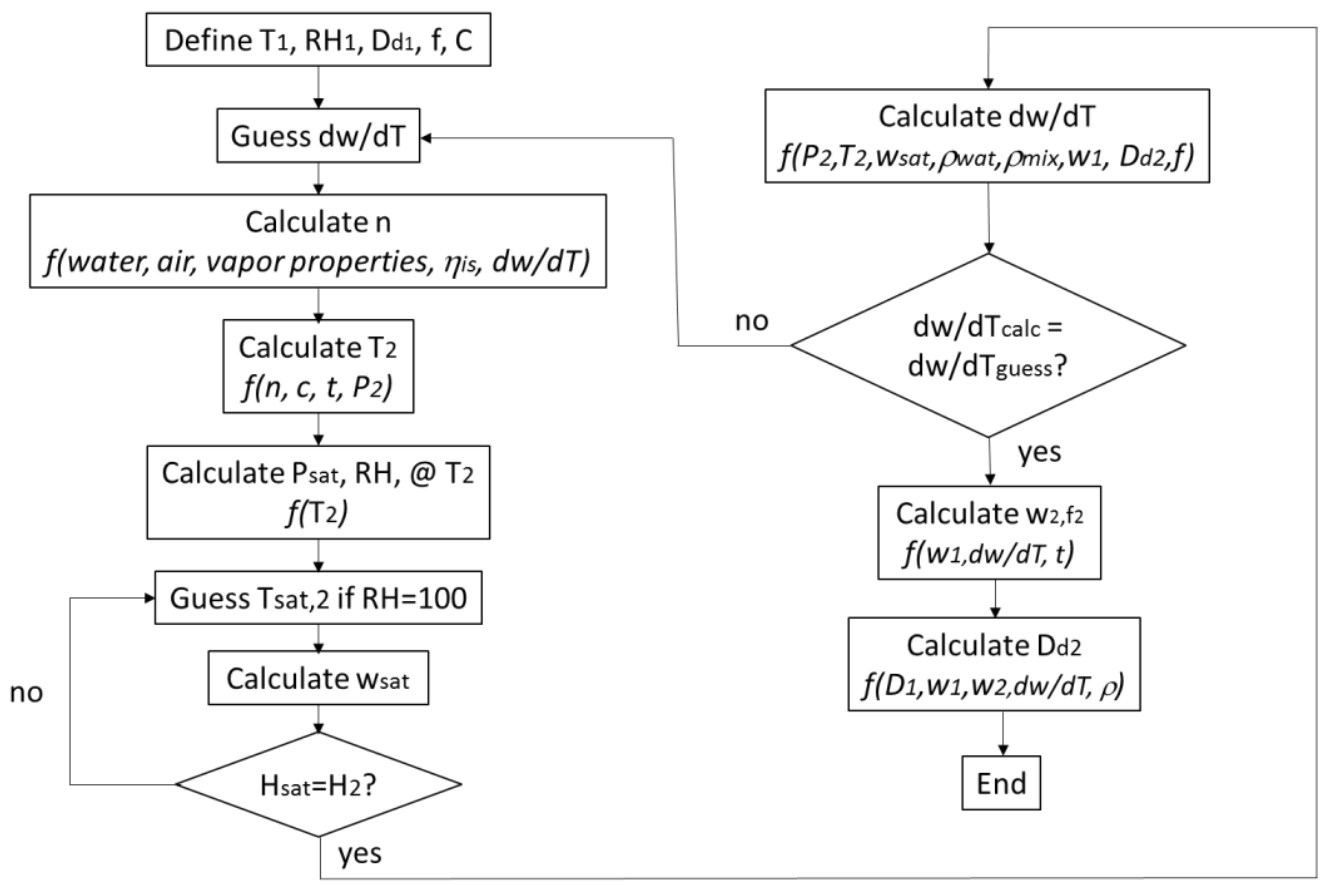

Figure B.1- Iteration Procedure followed for the compressor thermodynamic model.

\section{Appendix C. Variable vs Constant PR calculations}

Table C.1 Differences in booster exit temperature and pressure ratio for stand-alone compressor model and engine simulation model at varied ambient temperatures

\begin{tabular}{ccccc}
$\mathrm{T}(\mathrm{K})$ & $\begin{array}{c}\text { Stand-alone } \\
\text { compressor } \\
\text { (constant PR) }\end{array}$ & $\begin{array}{c}\text { Engine model } \\
\text { (varied PR) }\end{array}$ & $\begin{array}{c}\text { \% error in Booster } \\
\text { Exit Temperature }\end{array}$ & $\begin{array}{c}\text { \% error in } \\
\text { Booster PR }\end{array}$ \\
\hline 278 & 370.46 & 369.18 & $-0.35 \%$ & $2.80 \%$ \\
288 & 384.83 & 381.16 & $-0.96 \%$ & $2.75 \%$ \\
298 & 400.78 & 395.35 & $-1.37 \%$ & $2.67 \%$ \\
303 & 407.64 & 402.47 & $-1.28 \%$ & $2.65 \%$ \\
313 & 421.9 & 416.31 & $-1.34 \%$ & $2.67 \%$
\end{tabular}

\section{References}

[1] ICAO- International Civil Aviation Organization, 2013, 2013 Environmental Report, Aviation and Climate Change.

[2] Block N., D. A., and Igie, U., 2017, "Case For Exploring Compressor Water Injection For Airport Emission Reduction GT2017-64780,” Asme turbo expo: Power for land, sea and air., ASME, ed., American Society of Mechanical Engineers (ASME), Charlotte, p. TBC.

[3] Daggett, D. L., Fucke, L., Hendricks, R. C., and Eames, D. J. H., 2010, “Water Injection on Commercial Aircraft to Reduce Airport Nitrogen Oxides," Nasa/Tm-2010-213179, (March).

[4] Advisory Council for Aviation Research and Innovation in Europe, A., 2012, Strategic Research \& Innovation Agenda- Volume 1. 
[5] Nikolaidis, T., and Pilidis, P., 2014, "The effect of water ingestion on an axial flow compressor performance," J. Aerosp. Eng., 228(3), pp. 411-423.

[6] AGARD, 1995, Recommended Practices for the Assessment of the Effects of Atmospheric Water Ingestion on the Performance and Operability of Gas Turbine Engines, Neuilly-Sur-Seine.

[7] Roumeliotis, I., Alexiou, A., Aretakis, N., Sieros, G., and Mathioudakis, K., 2016, "Development and Integration of Rain Ingestion Effects in Engine Performance Simulations,” 137(April 2015), pp. 1-11.

[8] Liu, C., Li, X., Zhang, H., and Zheng, Q., 2017, "Heat and Mass Transfer Characteristics of Water Droplets in Wet Compression Process," ASME Turbo Expo 2017: Turbomachinery Technical Conference and Exposition, Charlotte, pp. 1-14.

[9] Utamura, M., Takehara, I., Horii, N., and Kuwahara, T., 1997, “A New Gas Turbine Cycle for Economical Power Boosting,” Am. Soc. Mech. Eng., 97-NaN-142, pp. 1-10.

[10] Sexton, M. R., Urbach, H. B., and Knauss, D. T., 1998, "Evaporative compressor cooling for NOx Supression and Enhanced Engine Performance for Naval Gas Turbine Propulsion Plants," Am. Soc. Mech. Eng., 98-GT332, pp. 1-10.

[11] White, A. J., and Meacock, A. J., 2004, “An Evaluation of the Effects of Water Injection on Compressor,” ASME, 126(October 2004).

[12] Zheng, Q., Sun, Y., Li, S., and Wang, Y., 2003, “Thermodynamic Analyses of Wet Compression Process in the Compressor of Gas Turbine,” J. Turbomach., 125(3), p. 489.

[13] Bagnoli, M., Bianchi, M., Melino, F., and Spina, P. R., 2008, "Development and Validation of a Computational Code for Wet Compression Simulation of Gas Turbines,” J. Eng. Gas Turbines Power, 130(1), p. 12004.

[14] Kim, K. H., Ko, H. J., and Perez-Blanco, H., 2011, “Analytical modeling of wet compression of gas turbine systems," Appl. Therm. Eng., 31(5), pp. 834-840.

[15] Kofar-bai, D. G., Zhang, H., Zheng, Q., and Abdu, S., 2017, "Flow Assessment on the Effects of Water Droplets on Rotor Region of Wet Compression," Transfer Phenomena in Fluid and Heat Flows III, Deffect and Diffusion Forum, pp. 131-147.

[16] Sun, L., Zheng, Q., Li, Y., Luo, M., Wang, J., and Bhargava, R. K., 2012, "Numerical Through Flow Simulation of a Gas Turbine Engine With Wet Compression,” ASME Turbo Expo, pp. 1-13.

[17] Wang, T., and Khan, J. R., 2010, “Overspray and Interstage Fog Cooling in Gas Turbine Compressor Using Stage-Stacking Scheme_Part I: Development of Theory and Algorithm,” J. Therm. Sci. Eng. Appl., 2(3), p. 31001.

[18] Wang, J., Zheng, Q., Sun, L., and Luo, M., 2012, “The Effective Positions to Inject Water Into the Cascade of Compressor," proceedings of ASME Turbo Expo, Denmark, pp. 1-14.

[19] Favorskii, O. N., Alekseev, V. B., Zalkind, V. I., Zeigarnik, Y. A., Ivanov, P. P., Marinichev, D. V, Nizovskii, V. L., and Nizovskii, L. V, 2014, "Experimentally Studying TV3 117 Gas Turbine Unit Characteristics at Superheated Water Injection into a Compressor," 61(5), pp. 376-384.

[20] Roumeliotis, I., and Mathioudakis, K., 2007, "Water Injection on Compressor Stage Operation," Trans. ASME, 129(July), pp. 778-784.

[21] Schnitzler, J. P., von Deschwanden, I., Clauss, S., Berna, F. ., Dohmen, H. J., and Werner, K., 2014, "Experimental Determination of a Four Stage Axial Compressor Map Operating in Wet compression," ASME Turbo Expo 2014: Turbine Technical Conference and Exposition, Dusseldorf, pp. 1-10.

[22] Kim, K. H., Ko, H. J., Kim, K., and Perez-Blanco, H., 2012, “Analysis of water droplet evaporation in a gas turbine inlet fogging process,” Appl. Therm. Eng., 33-34(1), pp. 62-69.

[23] Chaker, M., Meher-Homji, C. B., and Mee, T., 2002, "Inlet Fogging of Gas Turbine Engines- Part A: Fog Droplet Thermodynamics, Heat Transfer And Practical Considerations," ASME Turbo Expo, 
Amsterdam, pp. 1-16.

[24] Sanaye, S., and Tahani, M., 2010, “Analysis of gas turbine operating parameters with inlet fogging and wet compression processes,” Appl. Therm. Eng., 30(2-3), pp. 234-244.

[25] Hill, P. G., 1963, “Aerodynamic and Thermodyanmic Effects of Coolant Injection on Axial Compressors," Aeronaut. Q., November, pp. 331-348.

[26] Meacock, a. J., and White, a. J., 2006, "The Effect of Water Injection on Multispool Gas Turbine Behavior," J. Eng. Gas Turbines Power, 128(1), p. 97.

[27] Daggett, D. L., Ortanderl, S., Eames, D., Snyder, C., and Berton, J., 2004, "Water Injection : Disruptive Technology to Reduce Airplane Emissions and Maintenance Costs," SAE Tech. Pap. Ser., 1(3108).

[28] Roumeliotis, I., and Mathioudakis, K., 2010, "Evaluation of water injection effect on compressor and engine performance and operability," 87, pp. 1207-1216.

[29] Roumeliotis, I., and Mathioudakis, K., 2006, "Evaluation of Interstage water injection effect on compressor and engine performance and operability," Trans. ASME J. Eng. Gas Turbines Power, 128(4), pp. 849-856.

[30] Saul, A., and Wagner, W., 1987, "International Equations for the Saturation Properties of Ordinary Water Substance,” J. Phys. Chem., 16(4), pp. 893-901.

[31] Spalding, D. B., 1979, Combustion and Mass Transfer, Pergamon Press, London.

[32] Felder, J. L., Kim, H. D., and Brown, G. V., 2009, “Turboelectric Distributed Propulsion Engine Cycle Analysis for Hybrid-Wing-Body Aircraft," 47th AIAA Aerosp. Sci. Meet. Incl. New Horizons Forum Aerosp. Expo., (January), p. AIAA 2009-1132.

[33] Eckert, E., and Drake, R. M., 1959, Heat and Mass Transfer, Mc Graw-Hill, New York.

[34] Easa, 2012, EASA Type Certificate Data Sheet CFM56-5B and 5C Series engines.

[35] EASA, 2013, EASA Type Certificate Data Sheet Rolls Royce Trent 1000 Series Engines.

[36] Fishbeyn, B. D., and Pervystin, N. V, 1970, Determination of the Effect of Atmospheric Humidity on the Characteristics of a Turbofan Engine.

[37] Samuels, J. C., and Gale, B. M., 1950, Effect of Humidity on Performance of Turbojet Engines TN 2119, Lewis Flight Propulsion Laboratory, Cleveland Ohio.

[38] Bird, J., and Grabe, W., 1991, "Humidity Effects on Gas Turbine Performance,” Am. Soc. Mech. Eng., 91-GT329, p. 7.

[39] Sun, L., Zheng, Q., Li, Y., Luo, M., Wang, J., and Bhargava, R. K., 2012, "Numerical Through Flow Simulation of a Gas Turbine Engine With Wet Compression," pp. 1-13.

[40] Sun, L., Sun, T., Wang, Y., and Yang, W., 2016, "Numerical Simulation of Pollutant Emission of A Turbojet Engine with Water Injection,” ASME Turbo Expo 2016: Turbomachinery Technical Conference and Exposition GT2016, Seoul, pp. 1-9.

[41] Daly, M., 2015, Jane’s Aero-engines, Janes Information Group. 
2018-06-10

\section{Aero engine compressor cooling by water injection - Part 1: Evaporative compressor model}

Block Novelo, David Alejandro

Elsevier

Block Novelo DA, Igie I, Aero engine compressor cooling by water injection - Part 1: Evaporative compressor model, Energy, Volume 160, Issue October, 2018, pp. 1224-1235

http://dx.doi.org/10.1016/j.energy.2018.05.170

Downloaded from Cranfield Library Services E-Repository 